\title{
Cidade digital: a construção de shapefiles públicos como ambiente de ensino, pesquisa e extensão
}

\section{Digital City: the construction of public shapefiles as a teaching environment, research and extension}

\author{
Ademir Pereira dos Santos \\ Unitau e Centro Universitario Belas Artes SP, Brasil \\ dmi@hotmail.com \\ Denivaldo Pereira Leite \\ Centro Universitario Belas Artes, Brasil \\ Dirección de email
}

\author{
Ivan Augusto Alves Pereira \\ Centro Universitario Belas Artes, Brasil \\ ivanalves@gmail.com \\ Cesar HiroOkinaga \\ Centro Universitario Belas Artes, Brasil \\ okinaga77@hotmail.com
}

\begin{abstract}
We present here the first results of an academic field of research, developed by a working group of GEPTC, Landscape Study Group, Land and Culture, which brings together teachers and students from UNITAU (Universidade de Taubaté) and Centro Universitário Belas Artes de Sao Paulo. Combine traditional activities of research, collective and community, involving students of Architecture and Urban Planning courses (UNITAU and Belas Artes), to generate and test the application of Geographic Information Systems (GIS) to produce public shapefiles. From these shapefiles expected to generate three-dimensional modeling of Vila Edmundo and Vila Mariana to be the basis for exercise of urban intervention projects, aided by algorithms using Rhinoceros and Grasshopper, activity planned for the second stage of propositional character. The shapefiles made cooperatively and for public use, constitute a didactic and pedagogical experience of great interest to teaching, research and extension.
\end{abstract}

Keywords: Urban planning; Digital city: Shapefiles; GIS; TIC; GEPTC.

\section{Introdução}

Este trabalho relata uma experiência que é uma tentativa de se responder à crescente demanda para se adaptar os processos de projeto, adotados por arquitetos, às novas condições de rápidas mudanças das grandes cidades contemporâneas. Os profissionais necessitam adotar procedimentos flexíveis e adaptáveis a tais demandas, pois estas se avolumam rapidamente (Duarte, 2008). Este trabalho apresenta uma experiência em torno desta questão chave que é a experimentação e a adequação às diversidades.

O GEPTC, Grupo de Estudo Paisagem, Território e Cultura do Mestrado em Planejamento e Desenvolvimento Regional da Universidade de Taubaté, a UNITAU, reúne professores e alunos não só da pós-graduação. Está sediado no Departamento de Arquitetura da UNITAU e além dos alunos da graduação e do programa de Iniciação Científica mantém uma parceria com o Centro Universitário Belas Artes de São Paulo, possibilitando desenvolver pesquisas associadas, a partir do intercâmbio motivado por interesses comuns de projetos de pesquisas desenvolvidos nas duas instituições. Desde 2015 formou-se um grupo de trabalho no GEPTC que estabeleceu um programa de atividades para proporcionar a aproximação e o desenvolvimento de experiências simultâneas e colaborativas, envolvendo 0 uso de
GIS(Sistema de Informações Geográficas), as TICs (Tecnologias Informáticas de Comunicação) e o debate que envolve a reflexão sobre a urbanidade contemporânea, o papel e os instrumentos à disposição dos arquitetos, urbanistas e pensadores da cidade.

As primeiras atividades foram reuniões, viagens, vivências de espaços para estudos comuns, palestras e um workshop de dois dias de atividades reunindo aqueles que viriam a formar o atual grupo de trabalho. O passo inicial é a geração de uma cultura técnica comum que deve contemplar a adaptação das metodologias projetuais, já utilizadas por outros pesquisadores e empresas, envolvendo o uso de plataformas GIS e processos projetuais auxiliados por algoritmos aplicados a experimentos literalmente "domésticos". Ou seja, pensar e estudar a própria casa, ou melhor, a própria condição urbana em que estão inseridas as duas escolas, no caso, a Vila Edmundo em Taubaté, onde está situado o curso de Arquitetura e a Vila Marina, em São Paulo, onde está instalado o curso de Arquitetura e Urbanismo do Centro Universitário Belas Artes de São Paulo. Os estudos em paralelos permitiram estabelecer percepções por contraste, ressaltando as semelhanças, as diferenças, as continuidades e descontinuidades das duas espacialidades estudadas. Processo motivador, pois permite associações por "atrito", que atrai (pontos de contato por aproximação) e ao mesmo tempo repele (universos espaço temporais 
diversos ou opostos), transformando-se numa construção dialógica.

Porém, ao se usar os GIS e as TIC e busca-se não simplesmente a adaptação, mas ir além, pensar a cidade e a relação que os cursos de Arquitetura e Urbanismo têm com a comunidade e o meio onde funcionam, ou seja, onde se ensina e onde se aprende. Enfim, além da reflexão crítica pode-se também incorporar à própria missão universitária que é a produção de ensino, pesquisa e a extensão, no uso destas ferramentas. Afinal é uma característica intrínseca ao uso das TICs e do GIS a capacidade de integração e a interação social e do indivíduo.

\section{A Vila Edmundo e a industrialização de Taubaté}

A história da Vila Edmundo e seu entorno imediato, envolvendo a Companhia Taubaté Industrial e o eixo ferroviário contemplam pelo menos quatro momentos, cujas referências e cicatrizes convivem e estão sobrepostas no espaço urbano onde está localizado o Departamento de Arquitetura da Unitau.

O primeiro momento foi marcado pela construção da ferrovia, inaugurada em 1877, e depois pela construção de umramal, que buscando a menor inclinação possível, gerou espaços laterais ao longo do pátio de manobra e do leito da estrada de ferro. O ramal demandaria a ligação com o litoral norte, no caso a cidade de Ubatuba.

O segundo momento tem como marco o próprio loteamento da Vila Edmundo, executado por volta de 1880, e que se aproveitou dos espaços laterais gerados pelo ramal de Ubatuba, obra abandonada posteriormente. O nome da vila foi uma homenagem ao professor que morava nas cercanias, uma figura enigmática na história da cidade e do Brasil, o dinamarquês, Edmund Morewood.

O terceiro momento tem como referência a implantação e a configuração do conjunto fabril da própria Companhia Taubaté Industrial que se estendeu de 1891 até a década de 1970. A CTI não só se aproveitou da existência da Vila Edmundo para instalar-se, como a incorporou aos seus empreendimentos, que se estendiam praticamente até ao novo centro da cidade, que tinha como referência a Praça Santa Terezinha.

A CTI era uma tecelagem que se dedicou a produzir para o mercado interno, mas cresceu muito quando se aproveitou dos conflitos mundiais, ganhando fatias importantes do mercado externo.

O quarto e último momento ou camada, seria o da construção de uma variante para São Paulo e o viaduto sobre parte considerável da Vila Edmundo na década de 1970, sacramentando seu "sepultamento", que a transformou num ambiente que pode ser considerado como um NãoLugar, um espaço invisível, residual, parado no tempo.

Eis um dos motivos para o uso do termo "Arqueologia" para o trabalho proposto. Afinal um dos objetivos do trabalho é proporcionar a leitura e uma intervenção que revele (por meio de fotos, desenhos, vídeos) estas espacialidades e temporalidades que ali convivem ou dali foram eliminadas. Trazê-las, evidenciá-las, recuperá-las da invisibilidade cotidiana e re-significá-las, restituir (ou dar a pela primeira vez) a condição da existência.

\section{A Vila Mariana e as novas centralidades metropolitanas}

A Vila Mariana está entre os bairros paulistanos que têm como "marca de nascença" a relação com os antigos caminhos da Vila de Piratininga, fundada em 1554. Do surgimento da mais antiga aglomeração na região, datada século 18, às recentes transformações que o bairro sofreu, encontram-se aí os caminhos, e neles, o cruzamento da história dos meios de transporte com a peculiar urbanização da cidade de São Paulo.

Primeiro foi o Caminho do Mar no século 16 e o Caminho do Carro, quando esta ramificação das picadas que ligavam o planalto à baixada, passou a comportar veículos puxados por animais até o final do século 19. Depois vieram os trilhos dos bondes e em seguida os estridentes automóveis na primeira metade do século 20. Rapidamente os carros se multiplicaram após a década de 1950 e exigiram caminhos específicos, pavimentados e cada vez maiores, e, assim, essa região foi transpassada por avenidas a partir do alargamento de ruas que se alastraram por todos os recantos com os loteamentos das últimas propriedades rurais que caracterizavam a região como parte do cinturão verde de São Paulo. Depois das avenidas que foram acompanhadas pela verticalização, a Vila Mariana foi literalmente rasgada para esconder a construção do metrô na virada da década de 1970. Obra que avança o século 21, agora transversalmente em direção às margens, outrora "plácidas", do riacho do Ipiranga. A arquitetura da Vila Mariana é, portanto, testemunho deste processo marcado pela intensa transformação. Fato que justifica sua documentação e estudo do ponto de vista historiográfico.

\section{O uso do GIS e das TICs e os Shapefiles}

O Sistema de Informação Geográfica (aqui preferimos usar a sigla em inglês, GIS, como é mais conhecida na comunidade de pesquisadores e especialistas) é metodologia de trabalho computacional que é tomada a muitos anos por geógrafos, topógrafos, engenheiros agrimensores e demais profissionais que necessitem utilizar dados espaciais e sua rede de informações.

Percebemos, que nos últimos anos, não somente geógrafos e engenheiros tem dedicando-se a manusear tais ferramentas, e esta metodologia tem atraído cada vez mais arquitetos, não somente os interessados em desenho ou planejamento urbano, mas também aos dedicados a manipulação de dados do edifício.

O GIS tem se tornado nas ultimas décadas uma ferramenta tão embrenhada no ofício do urbanista como o CAD no ofício do arquiteto, tornando-se ambos quase sinônimos da própria atividade projetual resultante do trabalho profissional. O GIS, 
tal como afirma Almeida (2015) "trata-se de uma base de dados digital de múltiplas finalidades, na qual um sistema de coordenadas espaciais em comum é o meio básico de referência. Em razão de aglomerar dados oriundos de bases textuais (dados tabulares) a bases gráficas georreferenciadas (mapas, fotos aéreas e afins), consagrouse como um sistema altamente eficaz para tomada de decisões, ao permitir uma livre manipulação destes dados por meio de pesquisas e combinações variadas, sempre amparadas por uma representação gráfica, vetorial ou raster" (ALMEIDA, 2015, p. 46)

Por ser uma ferramenta que permite associar e integrar dados de natureza distintas às propriedades do espaço georreferenciado, o GIS tornou-se imprescindível à gestão das cidades, apesar das dificuldades que ainda apresentam o ensino e o uso generalizado, que não chegam, ou não têm uso contínuo nas prefeituras das pequenas e médias cidades. No entanto, a popularização do georeferenciamento através de softwares abertos como o QGIS e a disponibilização de dados por parte de empresas como a Google em serviços como o Google Maps e o Street View, por exemplo) fez com que o "geoprocessamento" fosse absorvido cotidianamente até pelo usuário mais incauto, devido ao uso dos smarts fones.

Mas infelizmente no Brasil,dentro dos cursos de arquitetura, os estudantes e professores acabam tomando contato com os avanços tecnológicos fora da universidade, como cidadãos ou consumidores, e pela condição de usuários e não pelo ambiente universitário da pesquisa e do ensino.

Outro fator que muito tem contribuído para uma reflexão sobre o domínio do ambiente urbano pelo usuário e cidadão é a interatividade possibilitada pelas Tecnologias Informáticas de Comunicação, TIC, que têm a telefonia móvel como suporte e elemento individual de interação e sociabilidade. O uso dasTIC têm imposto a revisão da própria condição urbana,redimensionando o exercício do poder público e da própria participação cidadã. Tem-se que entender o espaço urbano a partir da comunicação instantânea e da mobilidade como novas dimensões da gestão urbana. O uso da tecnologia como instrumento de colaboração e mediação dos desejos e conflitos que constituem a realidade, pois nos coloca em comunicação, nos globaliza e nos converte numa comunidade distinta. Como afirma Trachana (2014) "Las TIC puedem implementarla forma de interpretar y luego construir el mundo. Em un mundo cada vez más inconexo físicamente pero conectado tecnológicamente (virtualmente), la tecnologia está contribuyendo a reinventar ló común de los hombres y concebir um nova forma de estar juntos." (TRACHANA, 2014, p. 75)

O uso das ferramentas GIS, especialmente os softwares abertos) é apropriado para este contexto político e acadêmico que envolve o uso das TIC, por operar deforma integrada, usando interfaces diferentes, sejam elas alimentadoras de dados por meio manual (que envolve 0 próprio modo de se fazer um projeto arquitetônico tradicional) ou por meio de vínculo a bancos de dados dinâmicos (que permite conexões com outros sistemas de $\mathrm{TI}$, inclusive o BIM). (Cf. Almeida, 2015)

De acordo com Almeida (2015) "Esta característica marcante do GIS deve-se ao modo como seus arquivos nativos (shapefiles) relacionam-se entre si e com demais fontes. Um shapefile consiste basicamente em um arquivo principal ( ${ }^{*}$.shp), um arquivo-índice (*.shx) e uma tabela dBASE (*.dbf), havendo ainda outros arquivos acessórios que também podem estar associados a um mesmo shapefile. $O$ arquivo principal é um arquivo de acesso direto no qual cada um representa um conjunto de dados de uma mesma natureza de forma (ponto, linha ou polígono) com uma lista de seus vértices. O arquivo-índice tem a finalidade de indexar a leitura do arquivo principal, de modo a permitir que o software faça buscas rápidas no conteúdo deste. A tabela dBASE contém todos os atributos literais atribuídos às feições presentes naquele arquivo principal (Apud FOOTE; LYNCH, 1995; ESRI, 1998, in ALMEIDA, 2015, p. 48)

O município de São Paulo destaca-se no cenário brasileiro por disponibilizar seus dados geoespaciais em arquivos do tipo shapefile, com ampla quantidade de informações sobre a cidade e acessíveis via internet. Com tais bases e utilizando programas específicos e gratuitos como o Qgis, é possível visualizar as diversas camadas de informações, desde a rede hídrica, serviços de saúde, estrutura para o lazer, segurança, sistema de transportes entre outros. A disponibilidade de tais informações não é obrigatória para todos os municípios brasileiros, tornando o acesso ao sistema de informação georreferenciadas dos municípios uma tarefa para especialistas.

\section{Metodologia}

O objetivo primário deste trabalho, foi tentar preencher uma lacuna: já que as informações não estão disponíveis de maneira igual para os dois sítios estudados, resolvemos igualar as informações em bases manipuláveis e compartilháveis. São Paulo já possui sua base GIS disponível, como mencionado acima, porém Taubaté é carente destas informações. A atividade envolvendo as duas realidades, serviu como apoio para manipularmos os dados disponíveis de São Paulo, com informações que seriam pertinentes aos trabalhos dos alunos da Belas Artes. Já a expertise da atividade em São Paulo, auxiliaria a preparar uma base similar em Taubaté. O passo seguinte, que será realizada no primeiro semestre de 2017, é de utilizar as bases GIS como parâmetros para alimentar algoritmos que apresentem propostas para construção de abrigos sensíveis, por meio de fabricação digital, assim como tornar mais próxima da realidade a experiência do estudo urbano na universidade, dessa forma aumentando a interação entre o ambiente urbano e a escala da edificação.

\section{A produção de Shapefile como ambientes públicos}

Ao longo da pesquisa e da experimentação criamos uma base de dados do entorno dos respectivos cursos de Arquitetura e Urbanismo, georreferenciada e interativa, na 
qual o shapefile desempenha o duplo papel de interface de inserção e suporte de edição e simulação. O objetivo específico deste shapefile é reunir em camadas de informações, dados e fontes disponíveis em suportes e bases dispersas, disponibilizando-as para a comunidade de alunos, pesquisadores e moradores.

Para elaborar este dispositivo formou-se uma equipe de trabalho, a "Cidade Digital", no âmbito do GEPTC, Grupo de Estudo Paisagem, Território e Cultura, que reúne professores e pesquisadores da UNITAU (Universidade de Taubaté) e Centro Universitário Belas Artes de São Paulo. Os trabalhos combinam atividades tradicionais de investigação e atividade coletivas e comunitárias, envolvendo alunos da UNITAU e da Belas Artes, para testar a aplicação de Sistemas de Informação Geográfica (GIS).

Num primeiro momento foram realizados workshops e cursos rápidos para apresentação das ferramentas GIS e definição de fontes e rotinas de trabalho. Á partir da introdução dos alunos ao universo GIS os mesmos realizaram levantamentos e criaram uma base de edificações da Vila Edmundo à partir de fotos de satélite e Google Earth. Após esse momento, os alunos se dirigiram a campo para demais levantamentos como acervo histórico e gabarito das edificações. Essas bases foram construídas nos formatos KML (Google Earth) e CRV (Excel) posteriormente concatenadas e transformadas em shapefiles.

Posteriormente os arquivos do tipo shapefile foram disponibilizados em um drive virtual, de forma que seja possível a continuidade da inserção de novas informações, pela internet e por aplicativos instalados nos celulares, feitas pelos integrantes dos workshops ministrados pelos professores envolvidos na experiência, denominado por isto de "Cidade Digital".

Uma vez com os shapefiles consolidados, foram utilizadas duas ferramentas computacionais: Rhinoceros e seu plug in paramétrico Grasshopper (aliado a plug in Heron), e desenvolveu-se um algoritmo que a partir de uma entrada de dados de extensão shp (extensão de arquivos do tipo shapefile) gera-se como resultado final a modelagem tridimensional referente ao arquivo utilizado. Embora não estejam integrados em tempo real, é possível complementar - software Qgis para que o usuário possa ter uma possibilidade de trabalho e interação com a região estudada.

Após o preparo deste algoritmo, o grupo teve acesso a uma solução desenvolvida pela Autodesk, em sua ferramenta Infraworks 360 2016, que possui uma metodologia capaz de associar uma ferramenta online que gera topografia, e é possivel associar uma infinidade de possibilidades de entradas de dados, dentre elas os arquivos do tipo shapefile.

A questão é a forma que se pretende trabalhar a modelagem tridimensional, pois utilizando o algoritmo desenvolvido pelo grupo de trabalho, possuímos uma modelagem baseada em NURBS. Já utilizando o material produzido pelo sistema da Autodesk, o resultado é disponibilizado em uma modelagem que gera mesh. A utilização de uma metodologia ou outra certamente gerará discussões futuras em nosso próprio grupo, e que poderemos trazer para o SIGRADI em momentos futuros e mais oportunos.

\section{Resultados obtidos}

O resultado desta experiência é o primeiro shapefile público, da Vila Edmundo de Taubaté e a customização dos shapefiles existentes da Vila Mariana, em São Paulo. A partir destes shapefiles gerou-se modelagem tridimensional da Vila Edmundo e da Vila Mariana que servirá como base para utilização em exercícios de projeto auxiliado por CAD, usando BIM ou algoritmo utilizando Rhinoceros e Grasshopper, prevista para uma segunda etapa, de caráter propositivo.

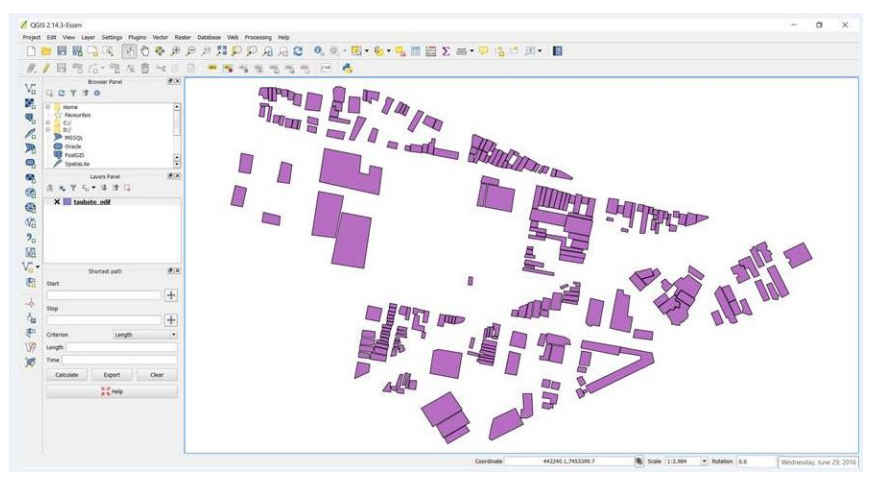

Figura 1: Shapefile das edificações da Vila Edmundo criado em exercício com alunos da Unitau.

Uma primeira aplicação do Shapefile Vila Edmundo está em pelo processo e já está sendo utilizada para ser a base da participação de um grupo de alunos e professores no URBAN 21, concurso promovido Revista Projeto Design para escolas de arquitetura. A participação em concursos tornou um dos eixos para o uso shapefile que é o desenvolvimento de projetos do EMAU - Arame, denominação do Escritório Modelo de Arquitetura e Urbanismo e Arquitetura da Unitau em processo de implantação.

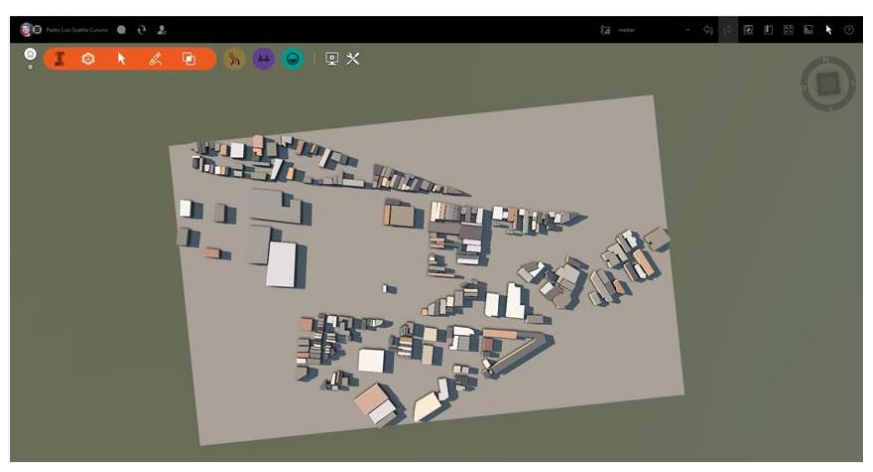

Figura 2: criação do ambiente 3d das edificações da Vila Edmundo á partir do software Autodesk Infraworks 360.

Do mesmo modo, no Centro Universitário Belas Artes, mais especificamente no âmbito do futuro programa de mestrado que contará com cursos de Arquitetura e de Comunicação, 
se está concebendo um Centro de Documentação, que deverá incorporar o uso do Shapfile Vila Mariana como uma vertente integradora dos estudos do bairro onde está instalada a instituição desde o final da década de 1980. A história da Vila Mariana será um dos fundos do Cedoc Belas Artes, também em processo de concepção.

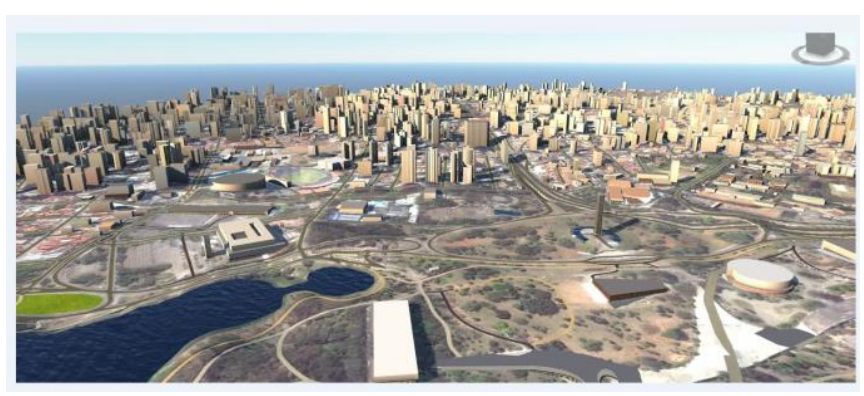

Figura 3: Maquete digital com elevações gerada por meio do Autodesk Infraworks, contendo edificações e topografia.

Neste processo identificamos três usos que atendem melhor a rotina de trabalho dos cursos de arquitetura: $O$ primeiro já relatado que é o entendimento do entorno dos prédios tanto da Unitau como da Belas Artes. Com isso acreditamos que podemos aproximar o ensino das matérias de urbanismo com conceitos como participação da comunidade e o fim das evidencias anedóticas.

O segundo uso identificado é a utilização dessas ferramentas para a criação de acervos. Tanto a Vila Edmundo como a Vila Mariana possuem grande repertorio de edificações históricas e essas ferramentas, aliadas a criação de banco de dados possibilitam a criação de inventários de arquitetura das edificações do entorno.

A criação de bases GIS também possibilita um melhor entendimento da relação entre edificações e o seu entorno e isso pode ser um facilitador na criação do projeto de arquitetura. Com bases contendo dados reais do entorno é possível gerar estudos de qualidade para a elaboração projectual, tal qual estudos de insolação, vento, iluminação e gabarito. Para possibilitar esse tipo de estudos, buscamos formas de gerar ambientes em três dimensões para essas bases construídas:

\section{O estudo do meio: atualidades do conceito de Lugar}

As particularidades históricas, geográficas e os significados que adquirem as experiências urbanas no Brasil, permitem individualizar cada experiência, ao mesmo que também permitem estabelecer aproximações a partir das semelhanças e das próprias diferenças. Longe de querer forjar comparações simplificadoras, trata-se de uma estratégia para se captar as características e idiossincrasias que conferem personalidade ao espaço e assim, dialeticamente formam e informam, ou seja, o transformam em Lugar.
Resguardadas a historicidade e as escalas diferentes das cidades de São Paulo (fundada em 1554, e hoje com cerca de 10 milhões de habitantes) e Taubaté (fundada em 1645, e hoje com cerca de 350 mil habitantes), pode-se traçar uma série de paralelos entre a Vila Mariana e a Vila Edmundo. Eram espaços periféricos na virada do século de XIX quando foram incorporadas à industrialização que transformou radicalmente o rumo e a velocidade da paisagem urbana depois do advento da ferrovia, (1867 em São Paulo e 1877 em Taubaté). Ambas as vilas desempenharam papéis semelhantes no âmbito da expansão da área urbana e da adoção do sistema de produção industrial como atividade principal da economia urbana na primeira metade do século $X X$. Ambas foram transformadas de espaços rurais e suburbanos em sedes de fábricas e local da moradia de operários que procuravam lugares próximos do trabalho para reduzir o custo de vida, neste caso, o valor gasto com o transporte.

As duas vilas também têm como marcos obras industriais que lhes conferiram a imagem de bairros da expansão industrial, que posteriormente alavancaram a transformação em nova centralidade, que são as fábricas e o transporte ferroviário. Se por um lado coube ao Matadouro Municipal e à linha de bonde correspondente, inaugurados em 1877, a transformação da região da atual Vila Mariana num bairro industrial, coube por outro, passagem da Estrada de Ferro Dom Pedro II, depois Central do Brasil (1877) e ao traçado da Estrada de Ferro Taubaté Ubatuba (1880), a origem da Vila Edmundo em Taubaté. Pela dimensão diminuta da Vila Edmundo não se pode falar de fábricas instaladas ali, porém, mas a Vila Edmundo foi absorvida quase que totalmente pelas instalações da CTI, Companhia Taubaté Industrial, a primeira grande indústria de Taubaté,ali instalada a partir de 1891. A Vila Edmundo teve suas quadras mais importantes do ponto de vista do traçado urbano, a estrela ou rotatória a la Haussmann, ocupadas pelas quadras-galpões da CTI, que nas demais quadras instalou também o seu conjunto esportivo e recreativo além das habitações, praticamente todas ocupadas por funcionários da tecelagem que ali funcionaram até a década de 1980. (Nota: o curso de Arquitetura da Unitau está sediado numa das quadrasgalpões remanescentes da CTI desde 1993).

\section{Projetos participativos e comunitários}

Interessa também analisar a experiência de se constituir bases de dados de forma cooperativa e amplamente acessível, para auxiliar na utilização de técnicas de projeto auxiliadas por algoritmo (AAD), na qual os alunos poderão criar posteriormente, especulações e propostas projetuais para revitalizar o entorno imediato das sedes dos respectivos cursos de Arquitetura e Urbanismo.

O exercício de construção de arquivos digitais georreferenciados de modo cooperativo e para uso público, os shapefiles, constitui-se num tipo de experiência didáticopedagógica de amplo espectro de interesses. Reúne-se objetivos como a resignificação e uso de meios cotidianos como os smartphones que possuem GPS e consequentemente geram arquivos georeferenciados 
possibilitando assim uma ampla participação interativa entre alunos e comunidade na criação de bases GIS, atentando assim 0 aluno para questões mais complexas $e$ fundamentais como a formação do futuro arquiteto e urbanista, compreendida a partir de uma ação que contemple a cidadania, que começa com a preocupação e o conhecimento do entorno da sua própria escola.

Outra grande vantagem observada, do ponto de vista acadêmico e didático, foi na confecção de maquetes físicas utilizando fabricação digital. Geralmente, nas escolas de arquitetura e urbanismo, modelos físicos (maquetes) são o meio mais utilizado para estudos de cenários urbanos adensados, porém demandam demasiado tempo para confecção de tais elementos, se utilizando métodos apenas analógicos.

Neste trabalho, onde passamos a utilizar não somente mapas impressos, mas iniciamos o trabalho utilizando arquivos baseados em sistemas GIS e modelagem tridimensional, percebemos que o caminho para fabricação digital utilizando corte a laser e impressão $3 \mathrm{~d}$, foi facilitado, uma vez que as bases digitais facilitaram a confecção de maquetes físicas.

Por ser uma base de dados digital com múltiplas camadas, na qual um sistema de coordenadas espaciais é compartilhado, o GIS mostrou-se capaz de associar informações diversas (incluindo mídias diferentes) e dar mais agilidade para compilar dados quantitativos, imagens, desenhos vetoriais e toda uma gama de informações que necessitariam diversas ferramentas computacionais diferentes para permitir o trabalho.

\section{Referências}

Almeida, F., \& Andrade, M. (2015) GIS como instrumento catalisador de uma Cidade Inteligente. SIGRADI 2015 [Proceedings of the 19th Conference of the Iberoamerican Society of Digital Graphics - vol. 1 - ISBN: 978-85-8039-135-0] Florianópolis, SC, Brasil 23-27 November 2015, pp. 46-50. http://papers.cumincad.org/cgibin/works/Show?sigradi2015 2.162.

Trachana, A. (2014) Urbe ludens. Somonte: Ediciones Trea, Espanha.

ESRI (1998). ESRI Shapefile Technical Description, Redlands, USA, p.1-34.

Foote, K.E., \& Lynch, M. (1995) Geographic Information Systems as an Integrating Technology: Context, Concepts, and Definitions, Boulder, USA. 